\title{
Influences of Cutting Speed and Material Constitutive Models on Chip Formation and their Effects on the Results of Ti6Al4V Orthogonal Cutting Simulation
}

Nithyaraaj Kugalur-Palanisamy, Edouard Rivière-Lorphèvre, Pedro-José Arrazola and François Ducobu

Nithyaraaj Kugalur-Palanisamy. University of Mons, Faculty of Engineering, Machine Design and Production Engineering Lab Belgium.

Corresponding author: Nithyaraaj.KUGALURPALANISAMY@umons.ac.be

Edouard Rivière-Lorphèvre. University of Mons, Faculty of Engineering, Machine Design and Production Engineering Lab Belgium

Pedro-José Arrazola. Mondragon University, Faculty of Engineering, Mechanical and Manufacturing Department - Spain

François Ducobu. University of Mons, Faculty of Engineering, Machine Design and Production Engineering Lab - Belgium

\begin{abstract}
The highly used Ti6Al4V alloy is a well know hard-to-machine material. The modelling of orthogonal cutting process of Ti6Al4V attract the interest of many researchers as it often generates serrated chips. The purpose of this paper is to show the significant influence of cutting speed on chip formation during orthogonal cutting of Ti6Al4V along with different material constitutive models. Finite element analyses for chip formation are conducted for different cutting speeds and are investigated with well-known Johnson-Cook constitutive model, a modified Johnson-Cook model known as Hyperbolic Tangent (TANH) model that emphasizes the strain softening behavior and modified Johnson-Cook constitutive model that consider temperature dependent strain hardening factor. A 2D Lagrangian finite element model is adopted for the simulation of the orthogonal cutting process and the results from the simulations such as calculated forces, chip morphologies are analyzed and are compared with the experimental results to highlight the differences. The results analysis shows that, the temperature in the secondary deformation zone is directly proportional to the cutting speed.
\end{abstract}

Keywords. Machining, Ti6Al4V, Finite Element Modelling, Abaqus, Cutting Force, Constitutive Models

\section{Introduction}

The Ti6Al4V one of the most widely used titanium alloy. The machining of this expensive alloy remains a major production industry concern because of the poor machinability characteristics. The Finite element modelling is widely employed by researchers [1] to reduce the experimental costs. Due to many factors that affect the machining, the finite element modelling of machining is a very complex process, often limited to the simplified orthogonal cutting configuration. Therefore, a well-defined flow stress model that considers the strain, the strain rate, the temperature, the hardening, the viscosity, and the loading history of the material is necessary in numerical modelling of metal cutting process. Dependency of the results to cutting parameters (and especially cutting speed) are important factors in determining machinability behaviors in addition to mechanical properties of a workpiece. A definitive constitutive model is always a principal factor in developing a finite element model [1]. Many material constitutive models have been developed in the recent years. Because of their simplicity and lucidity empirical models are widely considered.

The aim of this work is to investigate the influence of cutting speed ranging from $30 \mathrm{~m} / \mathrm{min}$ to $75 \mathrm{~m} / \mathrm{min}$ on forces and chip morphologies of Ti6Al4V alloy. This paper compares and analyze the finite element simulated results from Johnson-Cook model [2], the modified Johnson-Cook model from Calamaz et al. [3] that takes the strains softening behavior into account and the Modified Johnson-Cook from Hou et al. [4] that takes into account temperature dependent hardening factor and its coupled effects between strain and temperature with the experimental work carried out by Ducobu [5] for the cutting speeds of $30 \mathrm{~m} / \mathrm{min}, 50 \mathrm{~m} / \mathrm{min}, 75 \mathrm{~m} / \mathrm{min}$. The forces and chip morphologies from the nine simulations are compared and are validated with the experimental results. 
Influences of Cutting Speed and Material Constitutive Models on Chip Formation and thei...

\section{Numerical Modelling}

\subsection{Material Constitutive Models}

The empirical or phenomenological constitutive models are considered by many researchers for their simplicity and robustness. These models consider the variables of deformations such as the plastic strain $\varepsilon$, plastic strain rate $\dot{\varepsilon}$, and temperature $T$ under macroscopic scale.

\subsubsection{Johnson-Cook Constitutive Model (JC)}

The most widely used thermo-mechanical model that links plastic, viscous and thermal aspects observed during orthogonal machining process is the popular Johnson-Cook model [2]. Its flow stress is expressed by the following Eq. (1):

$$
\sigma=\left[A+B \varepsilon^{\mathrm{n}}\right]\left[1+C \ln \frac{\dot{\varepsilon}}{\dot{\varepsilon}_{0}}\right]\left[1-\left(\frac{T-T_{\text {room }}}{T_{\text {melt }}-T_{\text {room }}}\right)^{m}\right]
$$

Where $A, B, C, n, m$ are the constants that depend on the material and are determined by material tests. $A$ is the yield strength, $B$ the hardening modulus, $n$ the strain-hardening exponent, $C$ the strain rate sensitivity and $m$ is the thermal sensitivity. Constants $B$ and $n$ report the strain hardening. $T_{m e l t}$ and $T_{\text {room }}$ are the melting temperature and the room temperature respectively, while $\dot{\varepsilon}_{0}$ is the reference strain rate. The parameters for this model are given in Table 1 .

The JC model is meaningful in certain operating ranges of strains and strain-rates (strains up to 0.5 and strain rates lower than $10^{4} \mathrm{~s}^{-1}$ ) [1] but fails to capture high strain material behavior in machining, where the flow stresses are difficult to measure by existing material testing devices [2].

Thermal softening is defined as the flow stress drops with the increased temperature regardless of plastic strain. JC model does not account for softening observed at the strains and temperatures in the primary shear zone, which is characteristic of metals that exhibit shear banding [1]. This leads to modified or updated versions of Johnson-Cook model.

\subsubsection{Modified Johnson-Cook model by CALAMAZ (JC-Calamaz)}

A Modified version has been suggested by Calamaz et al. [3] by introducing a hyperbolic tangent (TANH) term into the Johnson-Cook flow stress model to incorporate strain softening effect at the high-speed machining process. The material flow stress for TANH model is expressed by the following Eq. (2):

$$
\sigma=\left[A+B \varepsilon^{\mathrm{n}}\left(\frac{1}{\exp \left(\varepsilon^{a)}\right)}\right)\right]\left[1+\operatorname{Cln} \frac{\dot{\varepsilon}}{\dot{\varepsilon}_{0}}\right]\left[1-\left(\frac{T-T_{\text {room }}}{T_{\text {melt }}-T_{\text {room }}}\right)^{m}\right]\left[D+(1-D) \tanh \left(\frac{1}{(\varepsilon+S)^{c}}\right)\right]
$$

Where,

$$
D=\left[1-\left(\frac{T}{T_{\text {melt }}}\right)^{d}\right] \quad \text { and } \quad S=\left[1-\left(\frac{T}{T_{\text {melt }}}\right)^{b}\right]
$$


Parameters $A, B, C, n, m$ have the same meaning of JC model and the new constants $a, b, c$ and $d$ are introduced by TANH law. The parameters for this model are given in Table 1. In the above equation, the first term, strain hardening function is modified by including flow softening at higher strain values, the second term on strain rate and the third term on thermal softening function remains unaltered and a fourth term on temperature-dependent flow softening condition were added.

\subsubsection{Modified Johnson-Cook model by HOU (JC-Hou)}

A temperature function into the work hardening term was introduced by Hou et al. [4] to describe the phenomenon of temperature dependent hardening effect for better prediction of flow stress behavior of Ti6Al4V alloy under loading condition of high strain rate and temperature. By coupling logarithmic strain hardening rate and thermal sensitivity coefficient along with the strain function a modified JC model was proposed (Eq. 3) by Hou et al.

The flow stress equation is expressed by the following Eq. (3)

$$
\sigma=\left[A+B\left(1+m_{1} \ln \frac{T}{T_{\text {room }}}\right) \varepsilon^{\mathrm{n}}\right]\left[1+C \ln \frac{\dot{\varepsilon}}{\dot{\varepsilon}_{0}}\right]\left[1-\left(\frac{T-T_{\text {room }}}{T_{\text {melt }}-T_{\text {room }}}\right)^{m}\right]
$$

Where, $m_{1}$ is the thermal sensitivity coefficient with the increasing strain, and the rest of all parameters have the same meaning as JC model. The authors concluded that strain hardening rate of Ti6Al4V alloy has no noticeable strain rate sensitivity but evidently temperature sensitivity. The parameters for this model are given in Table 1.

Table 1. Parameters adopted for JC model [6], JC-Calamaz [3] and JC-Hou [4]

\begin{tabular}{cccccc}
\hline & JC & \multicolumn{2}{c}{ JC-Calamaz } & JC-Hou \\
\hline$A(\mathrm{MPa})$ & 997.9 & $A(\mathrm{MPa})$ & 968 & $A(\mathrm{MPa})$ & 920 \\
$B(\mathrm{MPa})$ & 653.1 & $B(\mathrm{MPa})$ & 380 & $B(\mathrm{MPa})$ & 400 \\
$C$ & 0.0198 & $C$ & 0.02 & $C$ & 0.042 \\
$m$ & 0.7 & $m$ & 0.577 & $n$ & 0.633 \\
$n$ & 0.45 & $n$ & 0.421 & $T_{\text {room }}(\mathrm{K})$ & 0.578 \\
$T_{\text {room }}(\mathrm{K})$ & 298 & $T_{\text {room }}(\mathrm{K})$ & 298 & $T_{\text {melt }}(\mathrm{K})$ & 1933 \\
$T_{\text {melt }}(\mathrm{K})$ & 1878 & $T_{\text {melt }}(\mathrm{K})$ & 1878 & $m_{1}$ & 0.158 \\
& & $a$ & 1.6 & & \\
& & $b$ & 0.4 & & \\
\hline
\end{tabular}

The stress vs strain curve evolution for the JC, JC-Calamaz and JC-Hou at fixed temperatures of $T=573 \mathrm{~K}$ and $T=973 \mathrm{~K}$ for strain rate of $\dot{\varepsilon}=10000 \mathrm{~s}^{-1}$ is plotted in Fig 1 . 




(a)

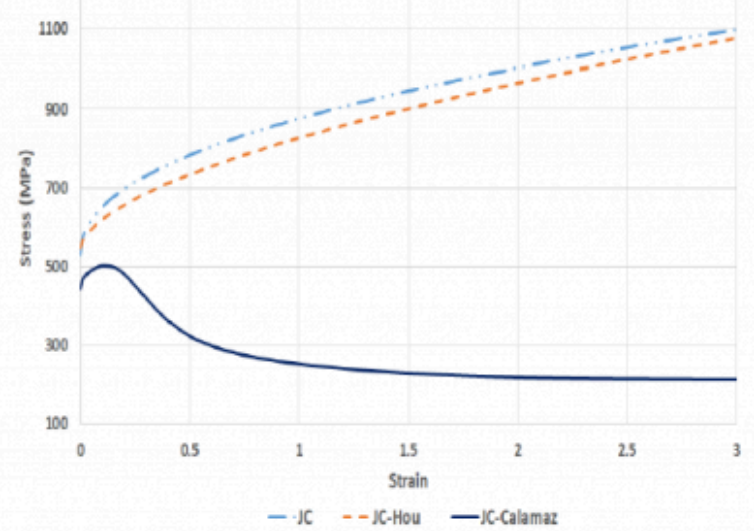

(b)

Fig. 1. Stress-strain curves of JC, JC-Calamaz and JC-Hou (a) at $T=573 \mathrm{~K}$ and $\dot{\varepsilon}_{0}=10000 \mathrm{~s}^{-1}$ (b) at $T=973 \mathrm{~K}$ and $\dot{\varepsilon}_{0}=$ $10000 s^{-1}[7]$

By comparing the stress-strain evolution curves in Fig.1 it is revealed that JC law, JC-Calamaz law that includes softening behavior and the JC-Hou law that consider temperature dependent hardening effect shows a significant difference in the evolution of stress with respect to strain at high temperature and strain rate. It is significantly important to note that the initial stress value of JC-Calamaz is very low when compared with initial stress value of other two constitutive models considered in this study. This might influence the calculation of forces and chip morphology.

\subsection{Finite Element Model and Cutting Conditions}

The finite element model (including information on damage model and friction conditions) was adopted from previous authors' work [6]. Tungsten carbide is selected as a tool material and the tool geometry is defined by the rake angle of $15^{\circ}$, the clearance angle of $2^{\circ}$ and the cutting edge radius of $20 \mu \mathrm{m}$ for cutting condition of uncut chip thickness of 60 $\mu \mathrm{m}$ with different cutting speeds of $30 \mathrm{~m} / \mathrm{min}, 50 \mathrm{~m} / \mathrm{min}$ and $75 \mathrm{~m} / \mathrm{min}$ which makes a total of nine models.

\section{Experimental reference}

The experimental reference is considered from the work of Ducobu [5]. The author adopted plunge turning conditions on a lathe to fulfill the hypotheses of the orthogonal cut with a lathe. This allows to evaluate the influence of the cutting speed. The cutting conditions are the same as for the simulations. Tungsten carbide tool is employed for machining of Ti6Al4V alloy. Three repetitions for each cutting speed were performed. The forces were measured with a dynamometer (Kistler 9257B), and useful part of the signal during cutting operation is considered to compute the RMS value of forces. The experimental setup is shown in Fig. 2. 

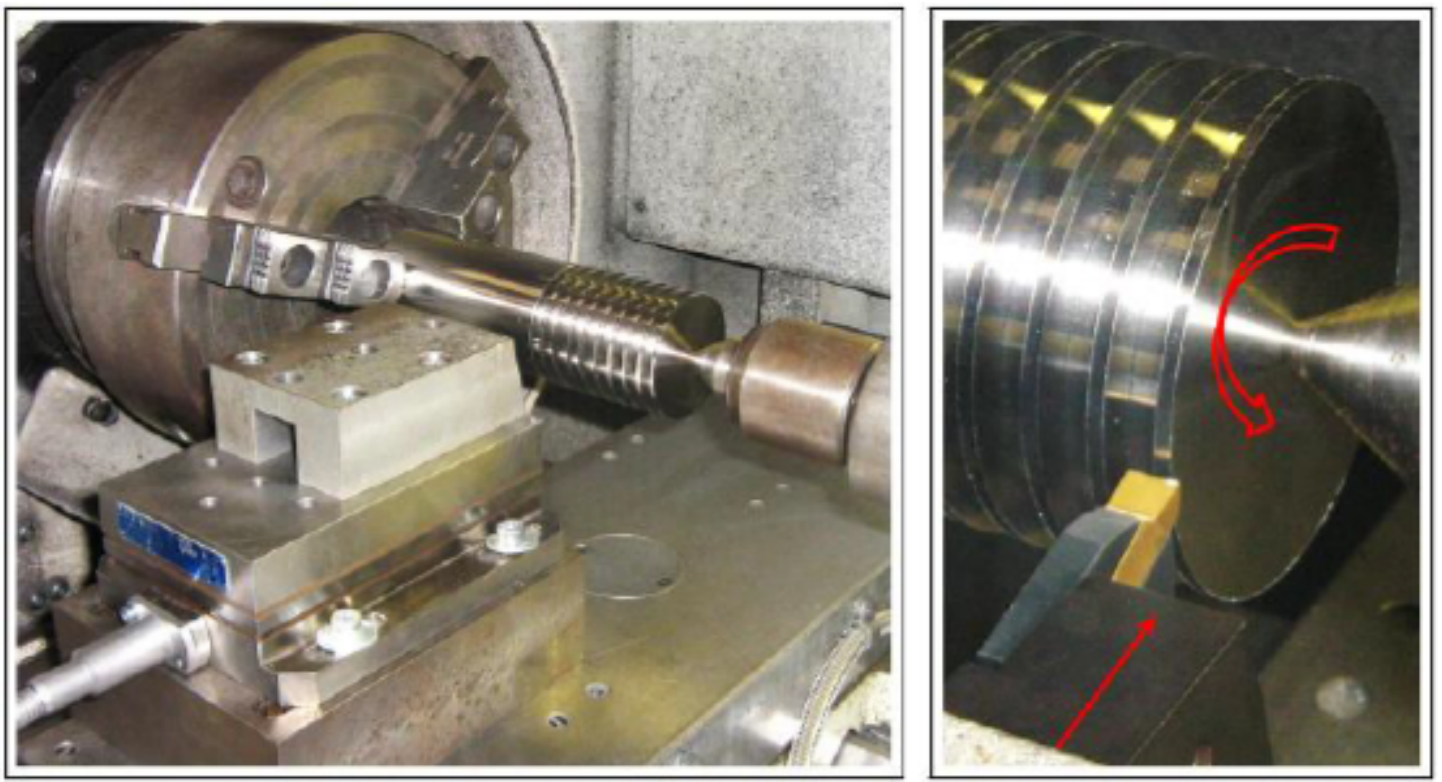

Fig. 2. Experimental setup [5]

Although segmented chips are often formed when machining Ti6Al4V, continuous chips were observed from the experiment. This is due to the rather low feed value of $60 \mu \mathrm{m} / \mathrm{rev}$. The RMS values of cutting force $\left(\mathrm{F}_{\mathrm{C}}\right)$, Feed force $\left(\mathrm{F}_{\mathrm{f}}\right)$ and chip thickness (h') are given in Table 3.

\section{Numerical Results}

Initially numerically simulated chips from JC and JC-HOU model with cutting speeds of $30 \mathrm{~m} / \mathrm{min}, 50 \mathrm{~m} / \mathrm{min}, 75 \mathrm{~m} /$ min are investigated and compared in Fig 3 and Fig 5. All the numerical chips are continuous as expected and the chip thickness decreases with increase of cutting speed for both JC and JC-Hou. The temperature distribution at the deformation zone is analyzed. As expected, the temperature is maximum in the secondary deformation zone for all three cutting speeds in the order of $75 \mathrm{~m} / \mathrm{min}>50 \mathrm{~m} / \mathrm{min}>30 \mathrm{~m} / \mathrm{min}$. The RMS forces values are calculated and compared in Table 2. It was observed that the magnitude of the cutting force for JC and JC-Hou shows decreasing trends with increase of cutting speed (In the order of $30 \mathrm{~m} / \mathrm{min}>50 \mathrm{~m} / \mathrm{min}>75 \mathrm{~m} / \mathrm{min}$ ) The feed force value of JC_30 is 52 $\mathrm{N} / \mathrm{mm}$ decreased to $42 \mathrm{~N} / \mathrm{mm}$ for JC_50 and then increased to $45 \mathrm{~N} / \mathrm{mm}$ for JC_75. where the feed force of JC-Hou_30 is $46 \mathrm{~N} / \mathrm{mm}$ which is increased to $67 \mathrm{~N} / \mathrm{mm}$ for JC-Hou_50 and then reduce to $43 \mathrm{~N} / \mathrm{mm}$ for JC-Hou_75. For feed force there is no definitive link with the cutting speed.

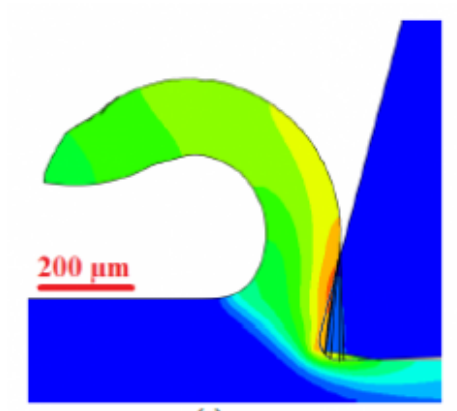

(a)

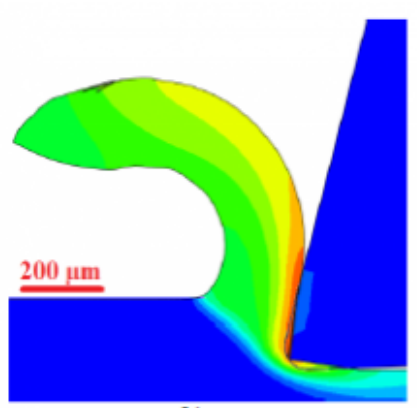

(b)

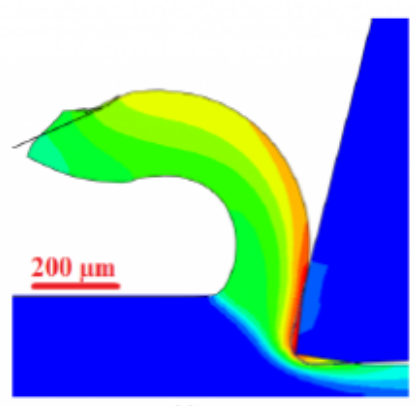

(c)

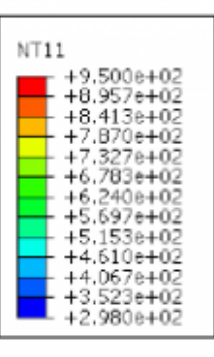

$2.980 \mathrm{e}+02$ 
Influences of Cutting Speed and Material Constitutive Models on Chip Formation and thei...

Fig. 3. Temperature contours (in $\mathrm{K}$ ) of the numerical chip by JC model

(a) $30 \mathrm{~m} / \mathrm{min}$; (b) $50 \mathrm{~m} / \mathrm{min}$; (c) $75 \mathrm{~m} / \mathrm{min}$

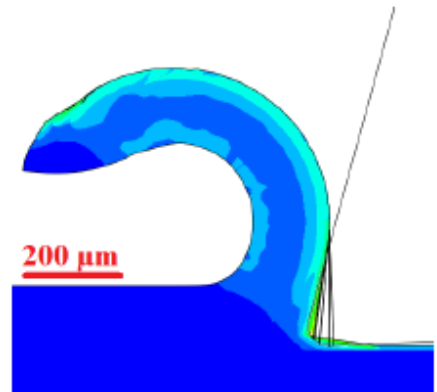

(a)

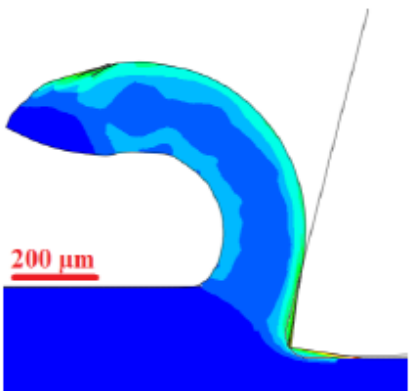

(b)

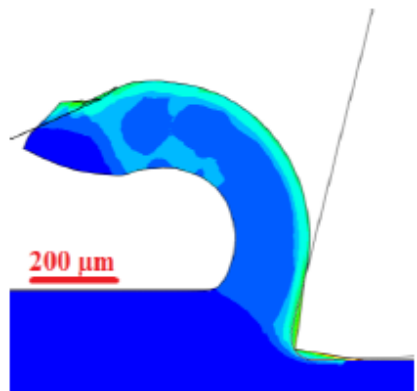

(c)

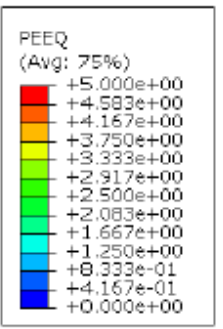

Fig. 4. Equivalent plastic strain contours of the numerical chip by JC model (a) $30 \mathrm{~m} / \mathrm{min}$; (b) $50 \mathrm{~m} / \mathrm{min}$; (c) $75 \mathrm{~m} / \mathrm{min}$

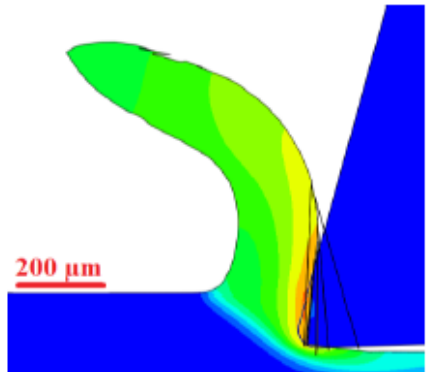

(a)

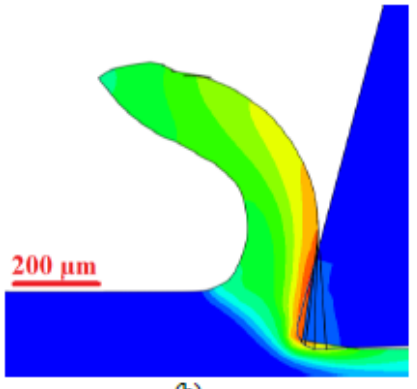

(b)



(c)

Fig. 5. Temperature contours (in K) of the numerical chip by JC-Hou model

(a) $30 \mathrm{~m} / \mathrm{min}$; (b) $50 \mathrm{~m} / \mathrm{min}$; (c) $75 \mathrm{~m} / \mathrm{min}$

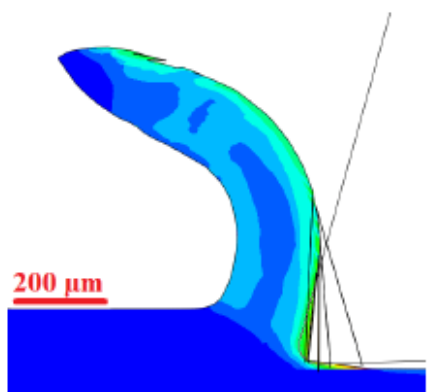

(a)

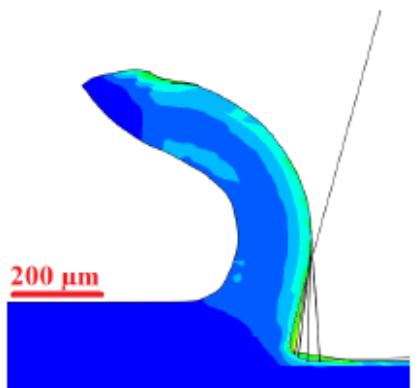

(b)

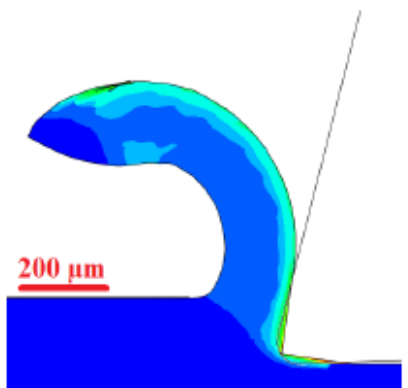

(c)

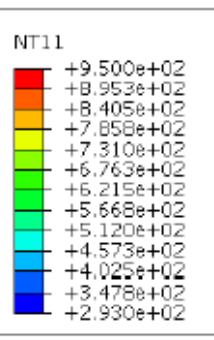

$+2.930 \mathrm{e}+02$

Fig. 6. Equivalent plastic strain of the numerical chip by JC-Hou model

(a) $30 \mathrm{~m} / \mathrm{min}$; (b) $50 \mathrm{~m} / \mathrm{min}$; (c) $75 \mathrm{~m} / \mathrm{min}$

The numerical chips of JC-Calamaz_30, JC-Calamaz_50, JC-Calamaz_75 is compared in Fig.7, The chips are slightly serrated. Indeed, the temperature differences are seen where the temperature is maximum in the secondary deformation zone for all three cutting forces in the same order of JC and JC-Hou models that is JC-Calamaz _75 > JCCalamaz _50 > JC-Calamaz _30. In addition, highly distorted and more elongated elements are observed in the chip as 
well as on the surface of the workpiece. The simulated cutting forces from JC-Calamaz models increases with increase in cutting speed (In the order of JC-Calamaz_75 > JC-Calamaz_50 > JC-Calamaz_75). The RMS value of feed force increases with the increase in cutting speed from $57 \mathrm{~N} / \mathrm{mm}$ for JC-Calamaz_30 to $65 \mathrm{~N} / \mathrm{mm}$ for JC-Calamaz_75 which is contrary to the JC and JC-Hou models. Indeed, the force ranges are highly distinct from experimental reference.

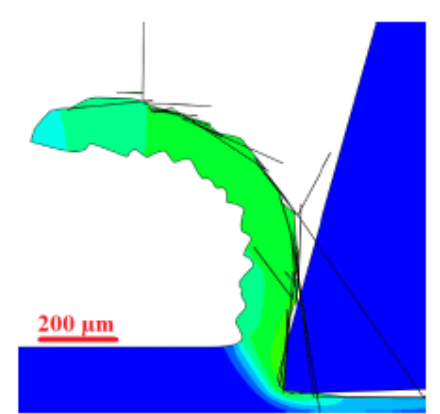

(a)

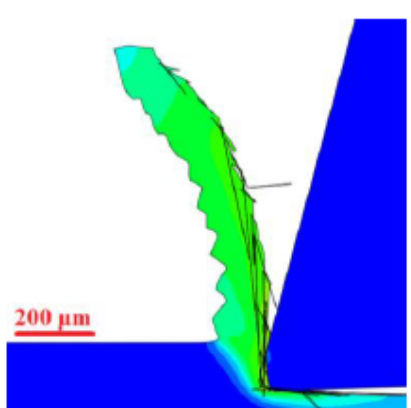

(b)

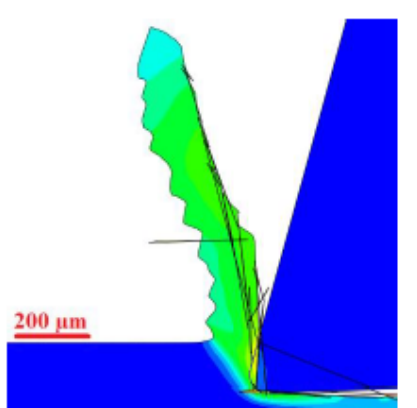

(c)

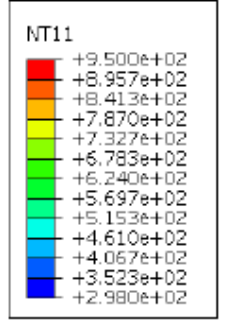

$+2.990 \mathrm{e}+02$

Fig. 7 Temperature contours (in $\mathrm{K}$ ) of the numerical chip by JCCalamaz model

(a) $30 \mathrm{~m} / \mathrm{min}$; (b) $50 \mathrm{~m} / \mathrm{min}$; (c) $75 \mathrm{~m} / \mathrm{min}$

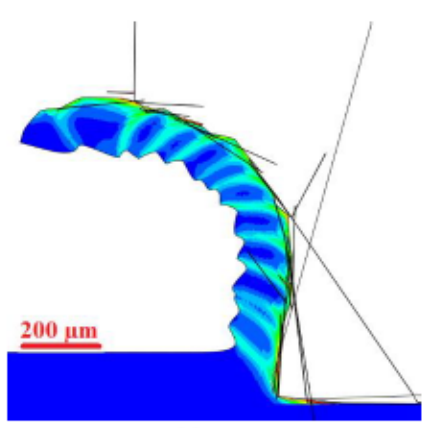

(a)

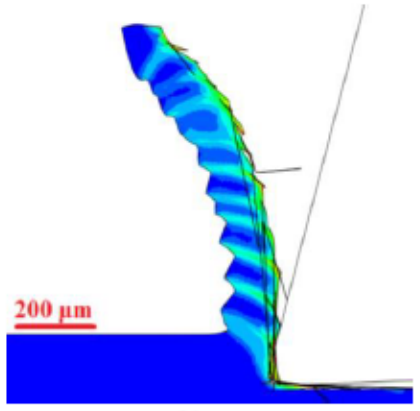

(b)

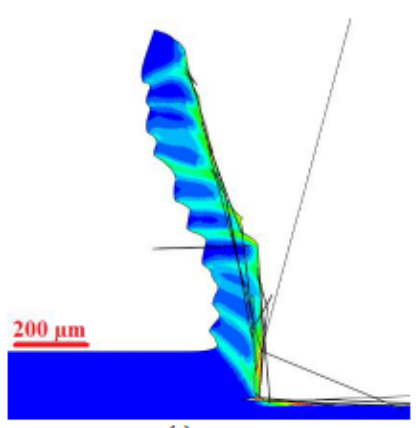

(c)

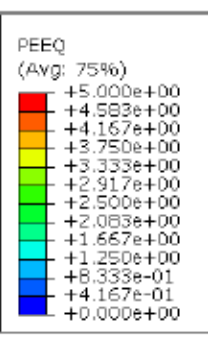

Fig. 8 Equivalent plastic strain contours of the numerical chip by JC-Calamaz model (a) $30 \mathrm{~m} / \mathrm{min}$; (b) $50 \mathrm{~m} / \mathrm{min}$; (c) $75 \mathrm{~m} / \mathrm{min}$

Fig 4, 6, 8 show the evolution of the chip with respect to equivalent plastic strain contours. The equivalent plastic strain distribution clearly depicts that JC-Calamaz models produces serrated chip whereas, JC and JC-Hou produces continuous chips. In addition, highly distorted and elongated elements are observed with the JC-Calamaz models.

Table 2. RMS cutting force $\left(F_{c}\right)$, feed force $\left(F_{f}\right)$ and chip thickness $\left(h^{\prime}\right)$ summary and $\Delta x$ differences with the experimental reference 
Influences of Cutting Speed and Material Constitutive Models on Chip Formation and thei...

\begin{tabular}{|c|c|c|c|c|c|c|c|}
\hline Models & $\begin{array}{c}\mathrm{Vc} \\
(\mathrm{m} / \mathrm{min})\end{array}$ & $\begin{array}{c}F c \\
(\mathrm{~N} / \mathrm{mm})\end{array}$ & $\begin{array}{l}\Delta \mathrm{Fc} \\
(\%)\end{array}$ & $\begin{array}{l}F_{f} \\
(\mathrm{~N} / \mathrm{mm})\end{array}$ & $\underset{(\%)}{\Delta \mathrm{F}_{\mathrm{f}}}$ & $\begin{array}{l}\mathbf{h}_{(\mathrm{mm})}\end{array}$ & $\begin{array}{l}\Delta_{\mathrm{h}^{\prime}} \\
(\%)\end{array}$ \\
\hline \multirow[t]{3}{*}{ EXPERIMENT [5] } & 30 & $127 \pm 2$ & - & $113 \pm 9$ & - & $0.078 \pm 2$ & - \\
\hline & 50 & $125 \pm 2$ & - & $117 \pm 12$ & - & $0.077 \pm 3$ & - \\
\hline & 75 & $128 \pm 1$ & - & $121 \pm 12$ & - & $0.075 \pm 2$ & - \\
\hline \multirow{3}{*}{$\mathrm{JC}$} & 30 & 107 & 16 & 52 & 54 & 0.079 & 1 \\
\hline & 50 & 101 & 19 & 42 & 64 & 0.072 & 6 \\
\hline & 75 & 95 & 24 & 45 & 63 & 0.068 & 9 \\
\hline \multirow{3}{*}{ JC-Hou } & 30 & 112 & 13 & 46 & 61 & 0.077 & 2 \\
\hline & 50 & 105 & 14 & 67 & 45 & 0.066 & 14 \\
\hline & 75 & 96 & 23 & 43 & 64 & 0.066 & 16 \\
\hline \multirow{3}{*}{ JC-Calamaz } & 30 & 82 & 35 & 52 & 54 & 0.060 & 23 \\
\hline & 50 & 85 & 32 & 57 & 51 & 0.055 & 29 \\
\hline & 75 & 86 & 31 & 65 & 46 & 0.053 & 29 \\
\hline
\end{tabular}

\section{Discussion}

From all the numerically simulated chips it was observed that the temperature in the secondary deformation zone increases with increase of cutting speed. It was explained by the phenomenon that when cutting speed increases, friction force increases and the strain rate in deformation zones also increase, these induce an increase in temperature in the deformation zones.

For all cutting speeds considered in this study, the variations of forces measured from the experiments are in the uncertainty range. Thus, the feed force and cutting force has no notable influence when the cutting speed increasing from $30 \mathrm{~m} / \mathrm{min}$ to $75 \mathrm{~m} / \mathrm{min}$. The RMS value of cutting force from all JC and JC-Hou numerical models considered in this study show as decreasing trend with increase in cutting speed, Whereas JC-Calamaz model shows an increasing trend with increase in cutting speed. The difference in the RMS values for JC and JC-Hou for the cutting speeds (30 m/min, 50 $\mathrm{m} / \mathrm{min}, 75 \mathrm{~m} / \mathrm{min}$ ) was in the range of $5 \%$ to $10 \%$ and for JC-Calamaz was in the range of $1 \%$ to $4 \%$. It is noteworthy that difference in their cutting force value trends is due to modification of thermal softening function of the JC model by adding temperature-dependent strain softening phenomenon, as an effect strain hardening predominates over the effect of thermal softening [8]. The stress strain evolution curve from Fig 1. clearly shows the influence of the strain softening on the stress level. Hence different stresses level leads to different cutting forces. In addition, it was observed that the feed force from JC-Calamaz also shows an increasing trend with cutting speed increment, but still, they are in the uncertainty range nevertheless, those values are far behind the experimental ones. It is also important to note that the difference between the numerically calculated force values and the experimentally measured force values may be due to the choice of the parameters of the constitutive models. Indeed, they are adopted from the references given in Table 1 and were not identified from the material samples employed for the experimental work.

The comparison of nine simulations with the experimental reference shows that the JC and JC-Hou models gave continuous chip, while JC-Calamaz models gave slightly serrated chip. From the flow stress equations, the JC and JCHou law produces continuous chip with uniform strain field, where JC-Calamaz law show a sequence of two unequal segments with high strain localised area and areas where the deformation is very low. However for qualitative comparision, a mean thickness value is calculated by taking the mean of peak and valley values of the JC-Calamaz chips. From the experiments, it was observed that the chip thickness decreases with increase in cutting speed. The chip thickness from numerical chips of JC and JC-HOU, JC-Calamaz also shows a decreasing trend with increase in cutting speed. When looking at the flow stress equations and the stress strain curves from Fig.1, temperature is a 
decreasing function of flow stress. Thus, when cutting speed increases, the temperatures increase which favors plastic deformation. This could increase side flow which leads to a reduction in chip thickness [9].

\section{Conclusion}

In this study, influences of cutting speed ranging from $30 \mathrm{~m} / \mathrm{min}$ to $75 \mathrm{~m} / \mathrm{min}$ with material constitutive models such as JC and modified JC constitutive material (JC-Hou, JC-Calamaz) on chip formation by numerical simulation are investigated and compared with the experiments conducted for uncut chip thickness of $60 \mu \mathrm{m}$. The results from the nine numerical simulations have been verified by comparing the RMS values of the cutting force, feed force, chip morphology, chip thickness with the experimental results.

1. The temperature in the secondary deformation zone increases when changing the flow stress model, and the temperature increment is in the order of JC-Hou > JC > JC-Calamaz. In addition to the temperature increases with increase of cutting speed from $30 \mathrm{~m} / \mathrm{min}$ to $75 \mathrm{~m} / \mathrm{min}$.

2. From the experiments, cutting speed has no significant effect on forces measurements.

3. The simulated forces from JC-Calamaz models are lower than JC and JC-Hou models. This is explained by the lower magnitude of the flow stress, while the parameters of the constitutive models are for the same material.

4. The JC-Calamaz model produce serrated chip contrary to the experimental chip morphology for the cutting conditions considered in this study.

5. Overall, the JC-Calamaz model is not well suited for this particular cutting condition.

\section{Acknowledgements}

Computational resources have been provided by the Consortium des Équipements de Calcul Intensif (CÉCI), funded by the Fonds de la Recherche Scientifique de Belgique (F.R.S.-FNRS) under Grant No. 2.5020.11.

\section{Bibliography}

[1] P.J. Arrazola, T. Özel, D. Umbrello,M. Davies, I.S. Jawahir, "Recent advances in modelling of metal machining processes", CIRP Annals, Volume 62, Issue 2, 2013, Pages 695-718, ISSN 0007-8506.

[2] Johnson GR, Cook WH. A constitutive model and data for metals subjected to large strains, high strain rates and high temperatures. in: Proceedings of the seventh international symposium on ballistics. The Hague, The Netherlands: 1983. 541-547.

[3] Calamaz M, Coupard D, Girot F. A new material model for 2D numerical simulation of serrated chip formation when machining titanium alloy Ti-6Al-4V. Int J Mach Tools Manuf 2008; 48:275-288.

[4] Hou X, Liu Z, Wang B, Lv W, Liang X, Hua Y. Stress-Strain Curves and Modified Material Constitutive Model for Ti-6Al-4V over the Wide Ranges of Strain Rate and Temperature. Materials (Basel) 2018 ;11(6):938.

[5] François DUCOBU- Doctoral Thesis "Contribution à l'étude de la formation du copeau de Ti6Al4V en coupe orthogonale Approches numérique et expérimentale pour la compréhension des mécanismes de coupe macroscopique et microscopique " Thèse de doctorat,.Faculté Polytechnique de Mons,2013. 
Influences of Cutting Speed and Material Constitutive Models on Chip Formation and thei...

[6] Seo S, Min O, Yang H. Constitutive equation for Ti-6Al-4V at high temperatures measured using the SHPB technique. Int J Impact Eng 2005; 31:735-754.

[7] N. Kugalur-Palanisamy, E. Rivière-Lorphèvre, F. Ducobu and P.-J. Arrazola" Influence of the Choice of the Parameters on Constitutive Models and their Effects on the Results of Ti6Al4V Orthogonal Cutting Simulation, Procedia Manufacturing, Volume 47, 2020, Pages 458-465, ISSN 2351-9789, https://doi.org/10.1016/j.promfg.2020.04.335.

[8] Komanduri, R., and Von Turkovich, B. F., 1981, "New Observations on the Mechanism of Chip Formation When Machining Titanium Alloys," Wear,69(2), pp. 179-188. (6)

[9] Kishawy, H.A., and Elbestawi, M.A. (1997b) "Effect of process parameters on chip morphology when machining hardened steel, MED, 6-2," Manufacturing Science and Technology, ASME (1997) 13-20.

PDF automatically generated on 2021-05-19 16:40:50

Article url: https://popups.uliege.be/esaform21/index.php?id=2424

published by ULiège Library in Open Access under the terms and conditions of the CC-BY License

(https://creativecommons.org/licenses/by/4.0) 